\title{
Social Networks and Its Effect in Teaching- Learning Processes at School Level
}

\author{
Ramesh Prasad Badoni \\ Lecturer Physics, \\ Department of Physics, \\ G I C Misras Patti Dehradun,Uttarakhand, India. \\ February, 2020, India
}

\begin{abstract}
Todays' Social networks (SNs) are the best platform that supports sharing interests, communications, collaborations and interactions in a normal life. Nowadays the teaching learning processes are converted as in flip and blended learning modes. Now teachers directly interact with student, parents and management to review the assignments of the students, their homework, progress chart and real time with quality achievements. We mapped the change in valuebased education (VBE), analyzed the impact of SNs that changing mindset of the educators and measured the core issues that matters in real life with respect to virtual life. The study shows that social media really imparted in videos, gaming, interactives, collaboration and sharing of the valuable applications and ICT tools. The SNs tools provides opportunities and affordable platform to enhance teaching learning processes in educational systems to provide universal and convenient education without any divides in our community. The SNs has been used in the class room for the tracking of student work, the post homework, upcoming planning and events, specific hashtag and creation of group with their real time contributions.

The continuous widespread use of SNs proves the one's social connections in new era of $21^{\text {st }}$ century [1]. This paper specially finds the teaching-learning happening in classroom using SNs in creation of knowledge, innovation, critical thinking and problem-solving skills in students. Simultaneously it will help the researcher to address the usage of SNs in Educational community of the globe. It has been indicated that there is rational of $\mathrm{SNs}$ in learning outcomes because the understanding of concepts learning increased, innovation trended in over the traditional teaching learning methodology and the dedication towards the job responsibilities improved. At the same time, it has been observed that there are some behavioral issues and ethics trending downwards like cyber bullying, sharpening anger and distraction from the basic skills.
\end{abstract}

Keywords: Social Media, ICT Tools, Social Networks, Cyber Ethics

\section{INTRODUCTION:}

In recent years SNs made a revolution in communication technology for the educational purposes. $4 \mathrm{G}$ and $3 \mathrm{G}$ and now looking forward to $5 \mathrm{G}$ Internet services provide the accessibility for the global society and raising more opportunities in teaching learning processes. SNs and Web tools are growing in school education with multiple way of communication like computers, tablets, mobile devices for the teachers and learners in variety of ways like sharing, collaborating and interacting virtually in the universe.

SNs now established the purpose with learning outcomes and it is now overstimulation for the students to stay focused on cyber security and their safety, decision making, discussions, digital prints, cyber bullying and plagiarism or thefts. The learners need the communication skills, software skills and well versed with writing, speaking and listening. SNs basically keeps identity, privacy, network infra and technological matter for educational teaching and learning processes [2] (Kevin, P. B., Lori B. H., and Bethany, V. S. (2010); Kuh, G.D. (1995). SNs and social media achieved that credibility as a source of information where everyone can have online or offline interactions that virtually take place. Now it's integral part of School and institutions to get dependence, to connect in groups to make education convenient. This is growing and students are getting benefits from online tutorials and resources shared via SNs. Usage of social media on mobile and computer like devices for the user interactions in different platform to get face to face engagements [3] (Teclehaimanot and Hickman,2011). The practice teachers in classroom are defined as "rich and delicate", presupposed a balanced performance, creating climate of openness and using pedagogical experience to create supportive structure for learning which is possible with trust and sensitivity among the teacher and learner [4] ( DeLaat, M.; Lally, V.; Lipponen, L.; Simons, R.J. 2007, p. 280).

Now the SNs are advancing education system and solving its issues in a pleasant manner so that the ethics, value-based education can sustain to inspire the learners for the forthcoming challenges in life.

\section{REVIEW OF LITERATURE:}

The influence of the social media in class room teaching is increasing day by day that means its usage is reinforcing the contents and materials for sharing and discussion [1] (Dr. K.Syamala Devi, E.Gouthami, V.Vijaya Lakshmi. 2019). Now major area of student participation increases in ebooks, blogging and showing improvement in learning style [5] (Brydolf, C. 2007). Most of the schools and academic institutions believe that the $\mathrm{SNs}$ offers values and collaborative learning using video, podcast, wikis, etc. [6] (Mike Moron, Jeff Seaman, and Hester Tinti-Kane 2011). The learners achieve effective cooperation in their studies and bade friends outside in twitter, google groups and other SNs and they have answers for multiple problem using social media [7] (Silius, K., Tervakari, A.M., and Miilumäki, T. (2009). Recent studies recommend that the social media is now itself an additional educational system and offering innovative and $21^{\text {st }}$ century-based learning ICT tools [8] (Redecker, C. 2009); Redeker. C., and Ala-Mutka. K. 2007). The survey on social media networks proved that 
its uses are like levers or simple machines at lowest cost and minimum training [9] (Qualman. E. 2009; Alexander.B. and Levine. A. 2008). SNs are flexible, easily available for individual and affordable like Facebook, Wikis and Blogs are used in institutions by the student in exploring their project works [10] (Alexander.B. and Levine. A. 2009). YouTube is a platform for learners to create and share videos in their daily life and in their studies as well [11] (Johnson, L Levine. A., Stone. S, and Smith. R.S. 2009). SNs are promoting virtual communities and effectively are capable to communicate synchronously and asynchronously [12] (Fogel \& Nehmad, 2009).

This is an impulse to every learner to remain active because it is potentially creating constructivism environment and at the same time it is promoting interaction among the communities [13]. The social media is an online learning platform where the teaching learning processes, sharing, values and sense of community are emerging with cohesion, spirt and quality education as per expected learning goals globally.

\section{BACKGROUND OF THE STUDY:}

The potential height of the SNs in knowledge construction are continuously making difference since last one decade in educational institutions. It has the capacity to understand now pedagogies and andragogy of the stakeholders in different schools and institutions. This paper is just to understand the teachers and educators around the schools of India and Asian countries with respect to their usage of social media networks in teaching learning processes. The study, of course; will give a spark to access the nature of social media most frequently used and how the SNs are playing vital role in their daily teaching learning work plan. In today's life most of the teachers remain uncertain about meaningful integration of ICT and SNs in their profession. They are using SNs as and when they feel it to be integrated but they are not really certain about the issues like media selection, ethics, cyber security and safety.

The most commonly SNs in practices are WhatsApp, twitter, Facebook, blogs, YouTube, google, Instagram, Telegram and others. On the other hand, some of the teachers are using ICT in meaningful ways, some are also involved in creating Massive Open Online Courses (moocs) and enrolled in different courses as well. For the evaluation point of view and social justice this task will definitely reach to useful findings [14] (Madge, C.; Meek, J.; Wellens, J.; Hooley, T.2009). Schools are now in the phase of adopting and integrating technologies and web tools in classroom teaching for real time understanding of the concepts [15] (Madhusudan G. Tandale, and Raghu Raman. 2016).

Consequently, it has been observed that there is need of study on SNs for in-service teachers and educators of school education system in Indian Schools and some of the Asian schools for the comparison of School education and their finding when they are using SNs.

\section{METHODOLOGY:}

In this study an online survey tool is used to get factual information about the individual teacher or an educator using SNs in real world. Around 270 responses collected through emails just to investigate the characteristics, behaviors and opinion on SNs of the teachers and educators from Indian Schools and Asian Schools as well. The 130 responses randomly sampled in order to make inferences about the teacher's point of view for SNs.

\begin{tabular}{|c|c|c|}
\hline $\mathbf{S} / \mathbf{N}$ & STATES/COUNTRY & $\begin{array}{c}\text { TOTALTEACHERS } \\
\text { NUMBERS }\end{array}$ \\
\hline 1 & Assam & 1 \\
\hline 2 & Bihar & 1 \\
\hline 3 & Chandigarh & 2 \\
\hline 4 & Chhattisgarh & 2 \\
\hline 5 & Delhi & 5 \\
\hline 6 & Gujarat & 18 \\
\hline 7 & haryana & 1 \\
\hline 8 & Jharkhand & 1 \\
\hline 9 & Maharastra & 1 \\
\hline 10 & Odisha & 2 \\
\hline 11 & Punjab & 3 \\
\hline 12 & Rajasthan & 2 \\
\hline 13 & Tamilnadu & 3 \\
\hline 14 & Telangana & 1 \\
\hline 15 & Uttar Pradesh & 2 \\
\hline 16 & Uttarakhand & 60 \\
\hline 17 & Viet Nam country & 3 \\
\hline 18 & Uk & 3 \\
\hline 19 & Ukraine & 7 \\
\hline 20 & Egypt / Qualubeya & 2 \\
\hline 21 & Croatia & 2 \\
\hline 22 & Romania & 2 \\
\hline 23 & Europa & 4 \\
\hline 24 & Buenos Aires & 2 \\
\hline
\end{tabular}

\section{TOTALTEACHERS NUMBERS vs. STATES/COUNTRY}

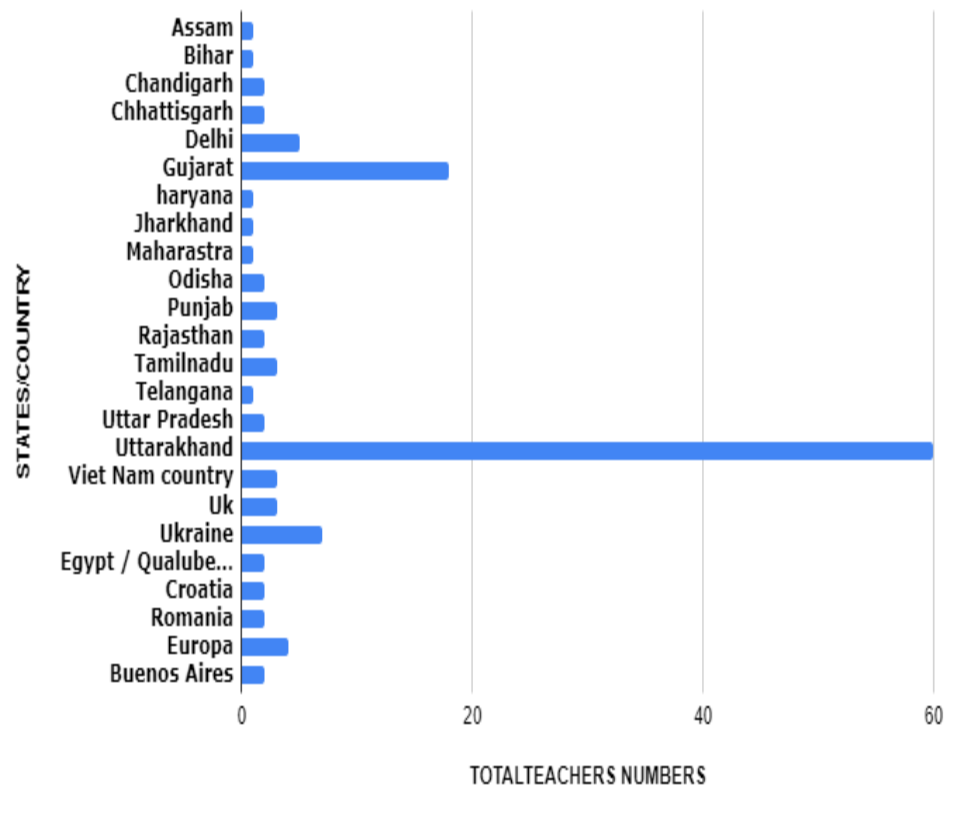

Table-1.1 Fig -1.1 
Table 1.1 and its plot shown as in Fig-1.1 is showing the maximum participation of the Uttarakhand state and Gujrat and rest of the Indian state and some of the Asian States are almost same in numbers in responding about the integration of SNs in teaching learning processes. Some of the educators almost thirty, were hesitant to show their interest as of organizational issues with ICT policies and its implementation in parallel to curriculum of the state education.

\section{ITEM RESPONSE ANALYSIS:}

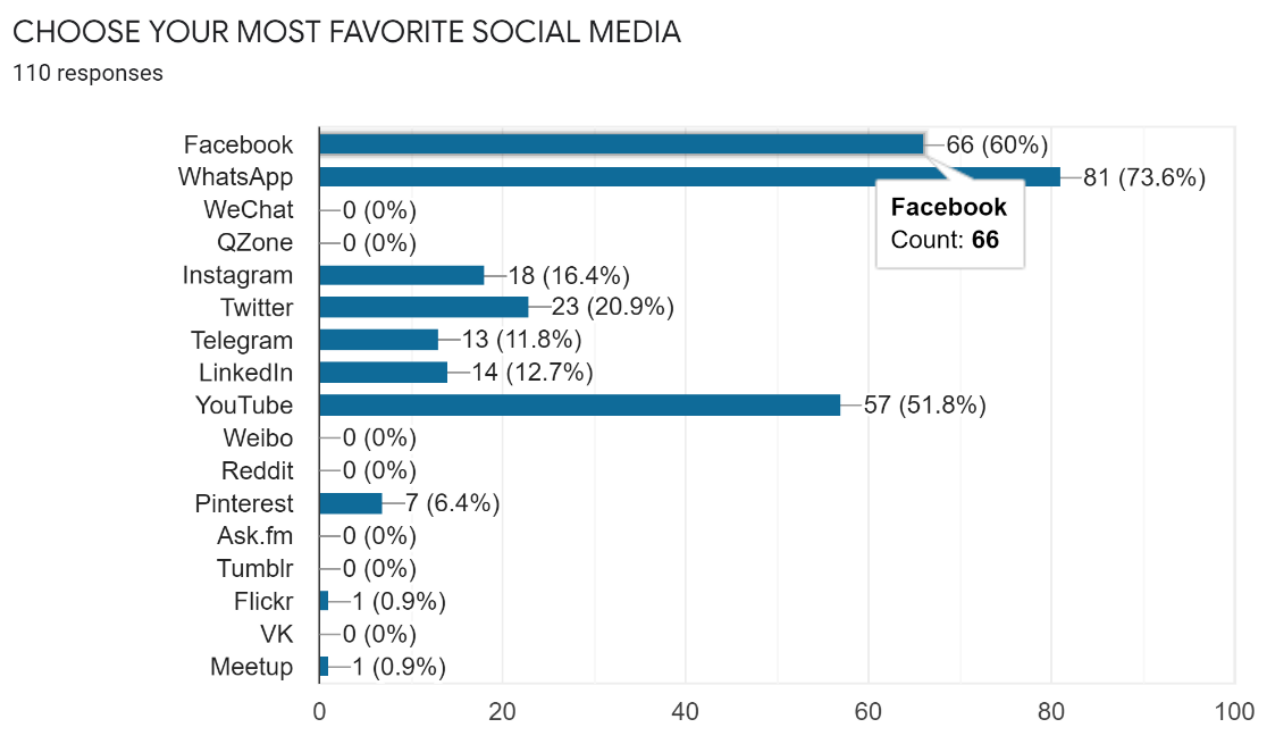

Fig -2.1

The first item was about the interest and user friendly SNs of the teachers, found as from fig-2.1 are WhatsApp is 73.6\%, Facebook is $60 \%$, YouTube is $20.9 \%$ and then Instagram is also favorite social media for them.

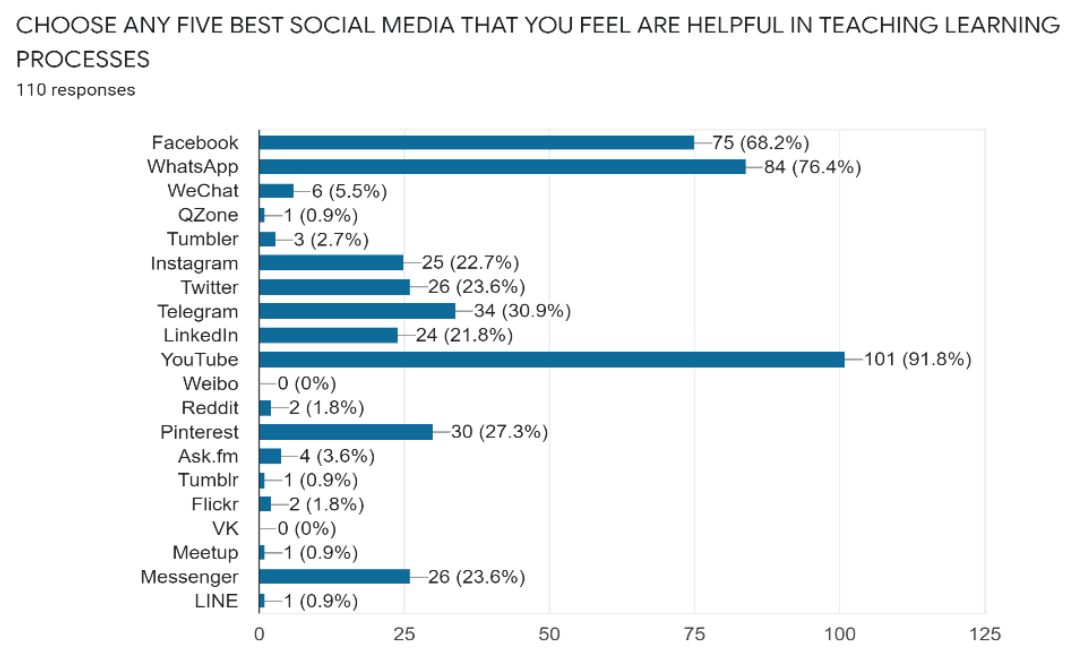

Fig -2.2

This item was just flashed to inquire the five best SNs what teachers are using during teaching and in real time situation with the learners. The Fig - 2.2 shows that most of the educators are inclined in the usage of YouTube (91.8\%) during their teaching what they felt are best resource for their purposes. Most of the content and resources shared through WhatsApp (84\%) and Facebook (68.2\%). Some of the SNs are like Telegram, Pinterest, Twitter, Instagram and Messenger almost used by an average of $27 \%$ educators. 
Today the most popular social networking site is

110 responses

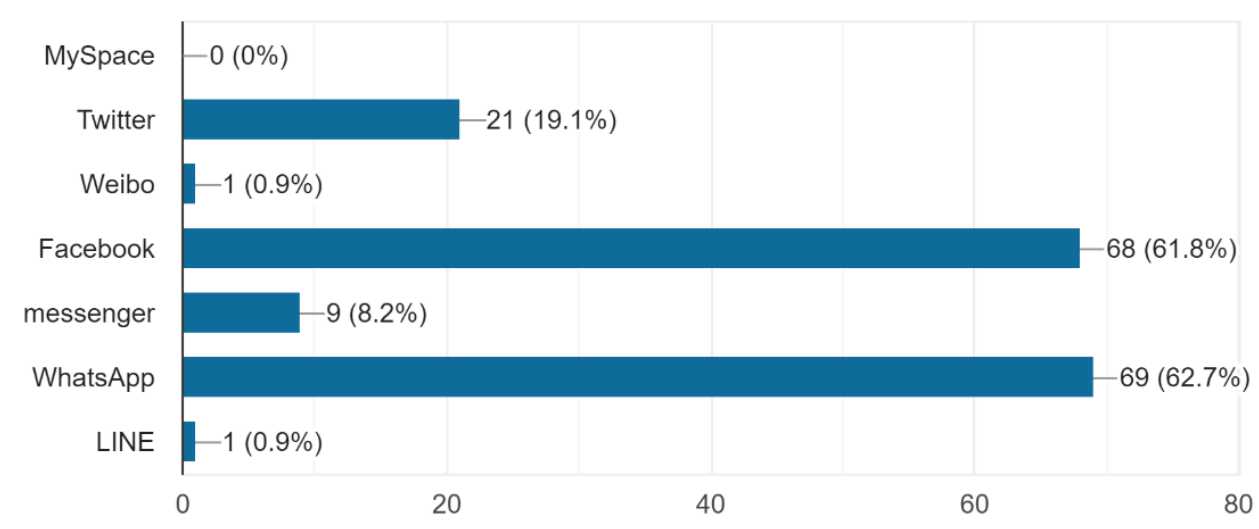

Fig -2.3

This item is just to asses the familiarity of the popularity of the SNs among the teacher in their workplace and what exactly they are using and influenced by are WhatsApp and Facebook $69 \%$ and $68 \%$ respectively. The Fig 2.3 reflects the user's interest also in Twitter and Messenger as well but less popular in teachers during teaching hours as well.

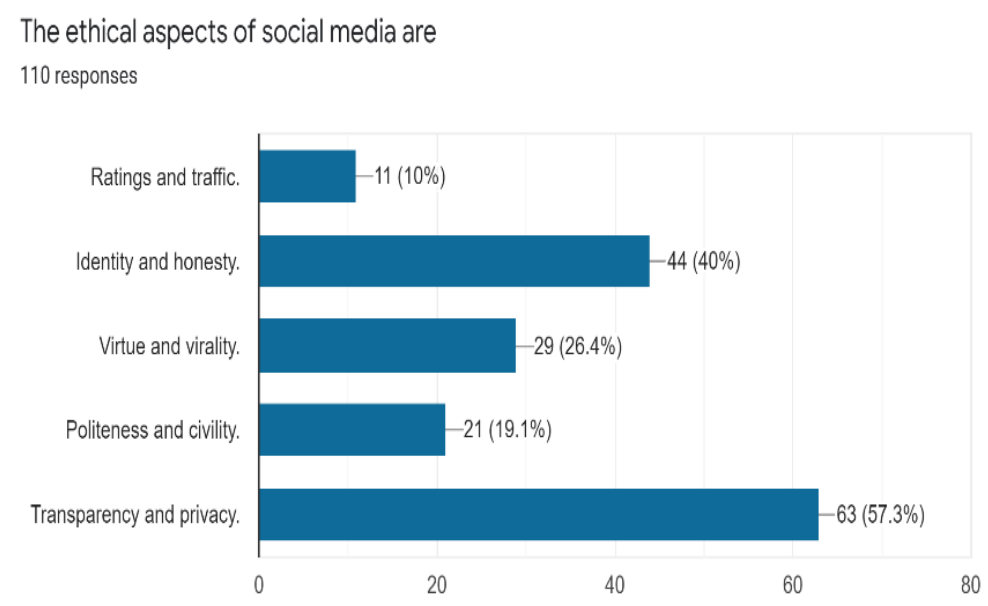

Fig -2.4

In this area the trend of responses is almost complexed because the teachers and educators replied in mixed way. That is because of lack of awareness and rare orientation in ethical aspects of SNs. The plot in Fig 2.4 represents that the teachers had belief in SNs like in its transparency and privacy $(57.3 \%)$ and $40 \%$ of educators feels that the SNs promotes social identity and honesty around $40 \%$. 
Which of the following is safe to post on a social networking site?

110 responses

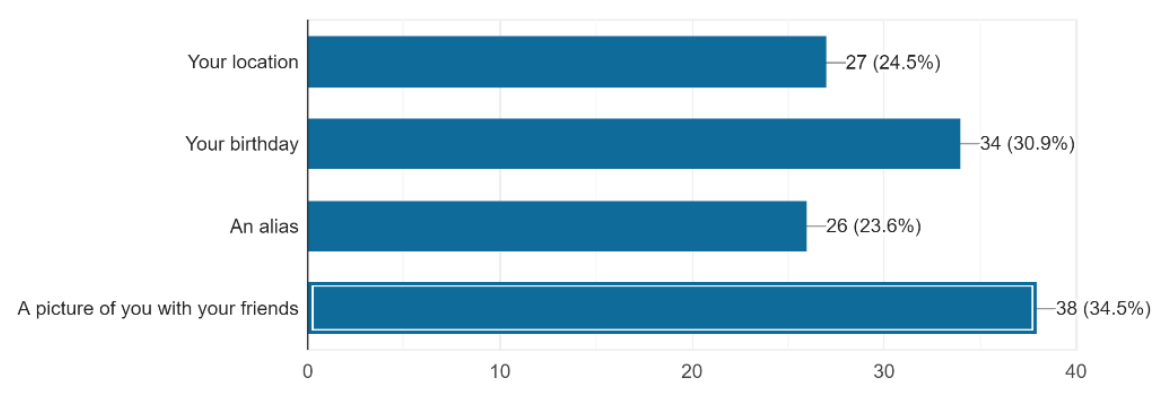

Fig -2.5

In case of safety and cyber security is concern the teachers and educators rely on the safe post on SNs where they believed that A self-picture and friends $34.5 \%$ and date of your birthday are the safest post on SNs. Around $31 \%$ felt the safe post in SNs are your date of birth and $24.5 \%$ felt that an alias is the best option to get in SNs that is why people are mostly tagging a photograph with friend helps in posting at SNs.

\section{As a teacher how much time you are giving for social media in job hours? \\ 110 responses}

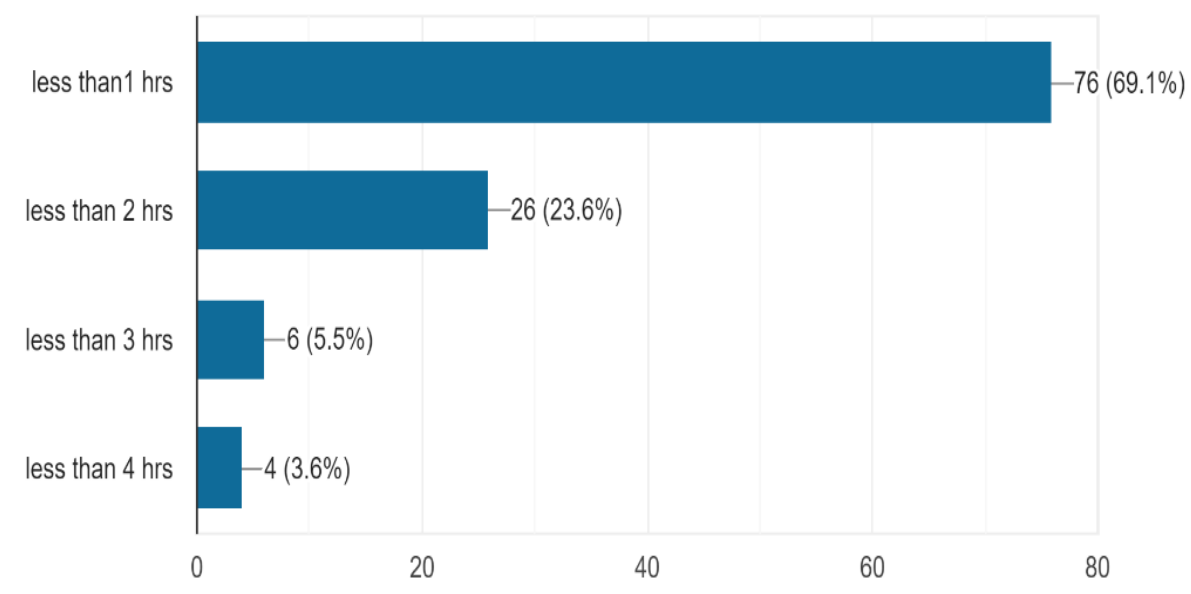

Fig -2.6

In this area it has been observed that most of the teachers across the states and Asian states are not using more than an hour in social media especially during the lecture or detailing the lesson in classroom teaching. The Fig -2.6 shows that the in average of population only $69 \%$ of teachers are using Social media and rest of the teachers are mostly doing their own tasks but only almost $8 \%$ of them are using social media during their teaching time. 
Which social media or web based apps your using for your teaching most?

110 responses

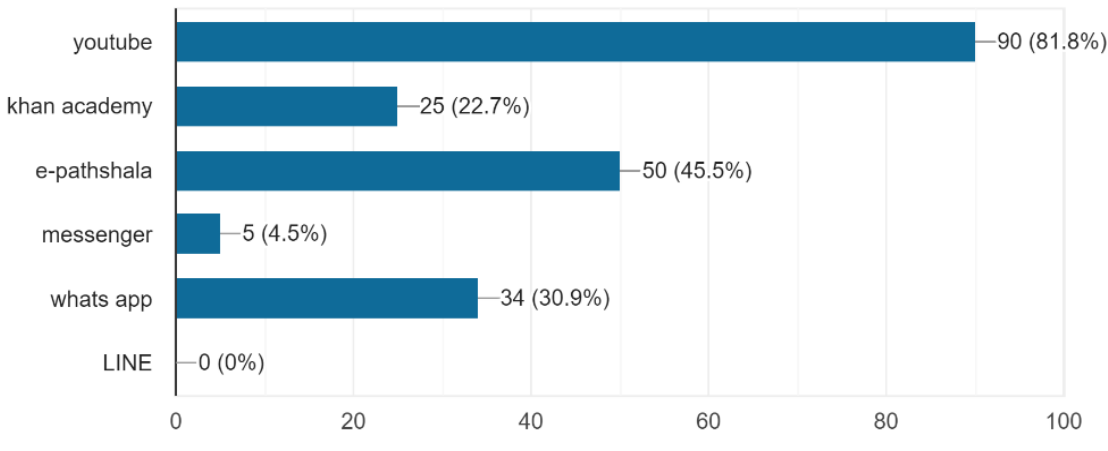

Fig -2.6

As it has been evident that most of the teachers in different institute of education are using social web-based media for their teaching as per need of the subject. Most frequently now every one in educational community are using YouTube around $81.8 \%$, E-Pathshala- $45.5 \%$, Whatsapp-30.9\% and khan Academy 22.7\% in teaching hours. These point values are shown in Fig 2.6 .

3. SOCIAL AND BEHAVIORAL ASPECTS OF SNS:

\begin{tabular}{|c|c|c|}
\hline \multirow{3}{*}{ Does the use of social media by employees affect the employee workplace behavior? } & Yes & 59.1 \\
\hline & No & 16.4 \\
\hline & Maybe & 24.5 \\
\hline \multirow{3}{*}{$\begin{array}{l}\text { Social networks are used for self-projection, most of the time by most of the members. Do } \\
\text { you agree? }\end{array}$} & Yes & 63.6 \\
\hline & No & 10 \\
\hline & Maybe & 26.4 \\
\hline \multirow{3}{*}{ Do you think social media is hampering teaching learning processes? } & Yes & 38.2 \\
\hline & No & 38.2 \\
\hline & Maybe & 23.6 \\
\hline \multirow{3}{*}{ Do yo think teachers are aware of cyber security? } & Yes & 38.2 \\
\hline & No & 38.2 \\
\hline & Maybe & 23.6 \\
\hline \multirow{3}{*}{ Do you think social media mislead young kids? } & Yes & 64.5 \\
\hline & No & 10.6 \\
\hline & Maybe & 24.5 \\
\hline
\end{tabular}

Fig 3.1

This section of investigation is applied for the analysis of quick responses to know the impact of Social media networks in the personal traits like the behavior of the teachers towards his fellow and student, the ethical uses of SNs and the inclusion of technology in classroom teaching. The graph shown in Fig -3.1 clearly explains that the there are positive change in personality of teachers and educators specially in behavior (59.1\%), in self-projection (63.6\%) and cyber security $(38.2 \%)$. The plot also indicates that there are hyper chances of misleading (64.5\%) in young kids when they are using SNs without cyber security (38.2\%). Most of the teachers are trending towards integration of SNs in teaching learning processes and they need more exposure that will increase the constructivism in educator's community. The addiction towards unwanted and unethical websites and SNs are influencing the social justice and inclusion of all challenges in the community. 
4. SELECTION OF SOCIAL MEDIA IN TEACHING LEARNING:

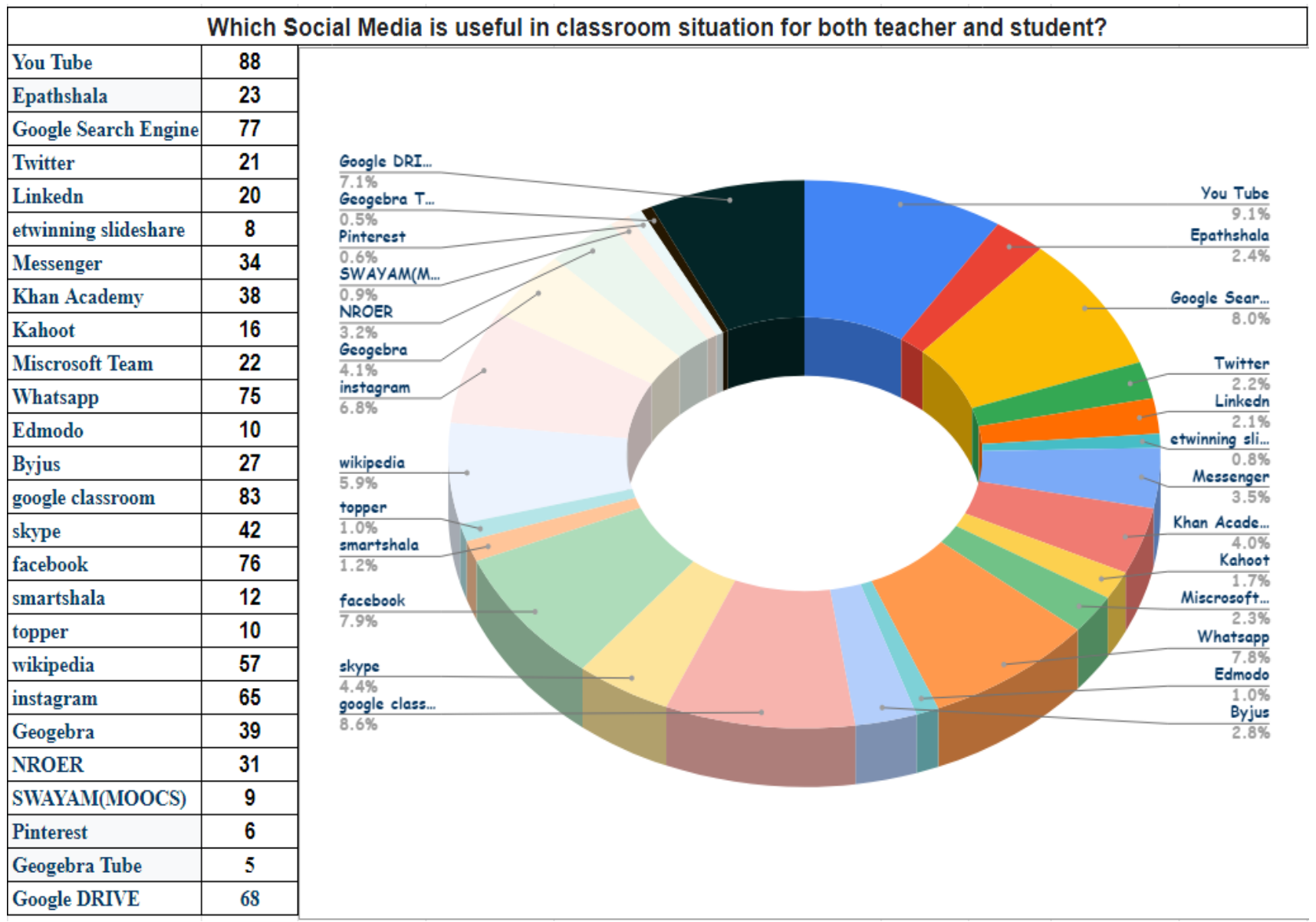

SNs selection and use of appropriate social media as per need of the curriculum, content, and level of the learner (like age, demography and physical presence) during the teaching in classroom by the teachers has been recorded and plotted here in Fig-4.1. the plot shows that the major segment of educational community is integrating the maximum from YouTube $(9.1 \%)$, Google class room $(8.6 \%)$, google search engine $(8.0 \%)$, and Google Drive $(7.1 \%)$. Some of the mobile applications, moocs, repository and $\mathrm{SNs}$ are contributing in education like EPathshala, NROER, SWAYAM, Wikipedia, GeoGebra Tube and Khan Academy in class room teaching -learning processes.

\section{CONCLUSION:}

The study on the integration of SNs in class room processes observed in mass of the teacher community that there are the following reasons of concern.

1. Teachers are smartly integrating YouTube, WhatsApp, Facebook and Google tools in teaching learning processes but at the same time less than $2 \%$ are developing learning resources for their subject area.

2. Creative and innovative learning happened as SNs became part of class room teaching resource.
3. Collaboration and independent thinking, problem solving skills and time management helps the teacher in job hours.

4. The SNs minimize the social and economical divides during teaching learning processes.

5. Ethical usage of SNs leads to security of the learner.

6. SNs effects everyone including young minds that is why they need proper and safe guided approach in handling the elements unwanted floating in SN platform.

The further scope of the study is to measure the competencies of the learner with the usage of SNs in their class room as per subject resources available in curriculum. The components of artificial intelligence and social audit will indeed be a part of study in future because now Machine learning, virtual learning and data science is empowering the Social Network.

\section{REFERENCES}

[1] Dr. K.Syamala Devi, E.Gouthami, V.Vijaya Lakshmi. 2019 C 2019 JETIR January 2019, Volume 6, Issue 1, www.jetir.org (ISSN-2349-5162)

[2] Kevin, P. B., Lori B. H., and Bethany, V. S. (2010). The Use of Alternative Social Networking Sites in Higher Educational Settings: A Case Study of the E-Learning Benefits of Ning in Education. Journal of Interactive Online Learning. 9, 151-170. 
[3] Teclehaimanot, B. \& Hickman, T. TECHTRENDS TECH TRENDS (2011) 55: 19. https://doi.org/10.1007/s11528-0110494-8.

[4] De Laat, M.; Lally, V.; Lipponen, L.; Simons, R.J. 2007. Online teaching in networked learning communities: A multimethod approach to studying the role of the teacher. Instr. Sci. 35, 257286.

[5] Brydolf, C. 2007. "Minding MySpace: Balancing the benefits and risks of students' online social networks", Education Digest, 73(2), 4.

[6] Mike Moron, Jeff Seaman, Hester Tinti-Kane. 2011. "Teaching, Learning, and Sharing: How Today's Higher Education Faculty Use Social Media", Pearson Learning Solutions.and Babson Survey Research Group, Boston, MA.

[7] Silius, K., Tervakari, A.M., \& Miilumäki, T. 2009. "Learning by doing as mobile with an Urban Computing Lab", Proceedings of International Technology Enhanced Learning Conference 2009, TELearn 2009. October 2009, Taipei, Taiwan.http://matriisi.ee.tut.fi/hypermedia//julkaisut/2009-siliusetal-learningbydoing-ucl.pdf.

[8] Redecker, C. 2009);:Redeker. C., and Ala-Mutka. K. 2007. "T1 Learning 2.0 - The Impact of Social Media on Learning in Europe. Policy Brief.
[9] Qualman, E (2009). (November/December 2008) "Web 2.0 Storytelling

A. Levine.

[10] Alexander, B., \& Levine, A. (2008, Nov-Dec). Web 2.0 storytelling: Emergence of a new genre. EDUCAUSE Review, 43(6), pp. 40, 42, 44, 46-48.

[11] Johnson, L Levine. A., Stone. S, and Smith. R.S. 2009, "Role of Social Media in Teaching-Learning Process"; Outlooks and Opportunities in Blended and Distance Learning.

[12] Fogel, J., \& Nehmad, E. (2009). Internet social network communities: Risk taking, trust, and privacy concerns. Computers in Human Behavior, 25(1), 153-160.

[13] Ferdig, R. E. 2007. Editorial: Examining social software in teacher. Journal of Technology \& Teacher Education, 15(1), 510. [15] Teclehaimanot, B., \& Hickman, T. 2011. Student-teacher interaction of Facebook: What students find appropriate. TechTrends, 55(3), 19-30.

[14] Madge, C.; Meek, J.; Wellens, J.; Hooley, T. 2009. Facebook, social integration and informal learning at university: 'It is more for socialising and talking to friends about work than for actually doing work'. Learn. Media. Tech..34, 141-155.

[15] Madhusudan G. Tandale, and Dr. Raghu Raman. 2016. 'Social Media in Teaching and Learning - A Study'. International Journal of Education \& Applied Sciences, Reseach. Vol.3. Issue 06. Pp 3142. 